\title{
Letramentos críticos na contemporaneidade: alternativa para o ensino de inglês na educação formal
}

\section{Simone Batista da Silva}

Professora Doutora na UFRRJ - Universidade

Federal Rural do Rio de Janeiro; Seropédica; Rio

de Janeiro; Brasil.

email: simonebatista@uol.com.br

Resumo: 0 presente artigo analítico tem por objetivo discorrer sobre os estudos dos letramentos, fazendo uma revisão diacrônica dessas investigações e apresentando os estudos teóricos contemporâneos nessa área, focando nos Letramentos Críticos, e em seus desdobramentos, tais como Multiletramentos e Letramento

Tridimensional. Com intenção de fornecer informação elementar e propor a discussão do tema aos que desejam se engajar em pesquisas investigativas teóricas e/ou práticas, pretende-se levantar a hipótese de que esses novos estudos possam subsidiar teoricamente novas práticas pedagógicas locais para o desenvolvimento dos letramentos em Língua Inglesa no ensino formal em contexto brasileiro.

Palavras-chave: letramentos críticos; ensino de língua inglesa; educação formal
Abstract: This analytical article aims at discussing the studies of literacies, having a diachronic review of these investigations and presenting contemporary theoretical studies in this area, focusing on Critical Literacies, and its unfolding parts, such as multiliteracies and Tridimensional Literacy. Intended to provide basic information and propose a discussion of the subject to those who wish to engage in theoretical and / or practical investigative research, we intend to raise the hypothesis that these new studies can theoretically support new local teaching practices for the development of literacies in English language in formal education in Brazilian context.

Key-words: critical literacies; English language teaching; formal education 



\section{Introdução}

Desde o século passado, os estudos dos letramentos vêm avançando tanto no Brasil quanto em outros países do mundo. Essa perspectiva de leitura e escrita ligada às práticas sociais, incluindo participação em atividades letradas na sociedade, vem sendo estudada e investigada cada vez mais incisivamente por pesquisadores tanto no Brasil quanto no exterior. Um dos nomes expoentes nos estudos de letramentos desde o século passado é Brian Street (1984), que define letramento como um termo equivalente às "práticas sociais e concepções de leitura e escrita” (STREET, 1984, p. 1, tradução nossa). ${ }^{1}$ Seguindo essa perspectiva do autor, o sujeito letrado, então, não é somente aquele que decodifica um texto verbal, ou que consegue associar grafemas a fonemas, mas aquele que consegue participar das práticas sociais que têm intricadas a escrita e a leitura, vivendo em estado de letramento. Assim, falar em letramento é falar em apropriação de uma tecnologia de informação e comunicação - neste caso, a escrita - para disseminar, compartilhar e trocar produções de sentido e impressões dos sujeitos em suas interações sociocomunicativas.

Menezes de Souza (2011a) diz que o termo letramento surgiu nos anos 1970 para se contrapor ao conceito de alfabetização. Conforme o autor explica, "surgiu o conceito de que a escrita e a leitura eram práticas sociais manifestadas de formas diferentes em comunidades diferentes e em contextos diferentes" (p. 286). No Brasil, Kleiman (2006) e Soares (1989) concordam que o termo Letramento tenha aparecido pela primeira vez nos trabalhos brasileiros em Kato (1986), e que, a partir de então, a terminologia letramento tenha começado a ser usada no Brasil tendo uma significação voltada para o âmbito social, ampliando a abrangência semântica do termo alfabetização, para exprimir não mais somente leitura e escrita como decodificação e
1 "social practices and conceptions of reading and writing" 
2 "literacy is a matter of social practices" codificação, mas como "o estado ou a condição que adquire um grupo social ou um indivíduo como consequência de ter-se apropriado da escrita" (SOARES, 1989). Por esse motivo, Menezes de Souza (2011a; 2011b) salienta a adequação do uso do vocábulo Letramentos, no plural, já que os letramentos são contextuais e relacionados a grupos sociais e suas relações sociocomunicativas. Também Takaki (2012) ressalta essa característica dos letramentos, ao afirmar que "letramento refere-se a um contínuo processo que representa diferentes tipos de habilidades e conhecimentos (...) sempre situacional, ou seja, localizado em contextos socioculturais específicos (...)" (p.7, grifo do autor).

No final dos anos 1990, alguns pesquisadores das áreas de Educação, de Linguagem e de Estudos Sociais e Antropológicos, inspirados nos projetos educacionais de Paulo Freire no Chile e no Brasil, começaram a revisitar os estudos de letramentos realizados até então, trazendo uma perspectiva pós-crítica de Educação, tendo em vista as novas configurações sociais, econômicas, políticas, identitárias e epistemológicas surgidas em decorrência dos processos de globalização e das interações comunicativas permitidas e sustentadas pelo advento das novas Tecnologias de Informação e Comunicação - TICs. Desde então, esses estudos contemporâneos dos letramentos vêm sendo desenvolvidos por nomes tais como o New London Group (1996), Alan Luke e Peter Freebody (1997), Cervetti, Pardales e Damico (2001), Lankshear e Knobel (2006), Kress e Van Leeuwen (2007), Monte Mór (2011), Menezes de Souza (2011a; 2011b), Jordão (2011), Silva (2012), entre outros que também compreendem que "letramento é uma questão de práticas sociais" (LANKSHEAR e KNOBEL, 2006, p. 12, tradução nossa). ${ }^{2}$

O objetivo deste trabalho analítico é discorrer sobre os estudos dos letramentos, fazendo uma pequena 
revisão diacrônica dessas investigações, apresentando as perspectivas contemporâneas nos estudos de letramentos, e focando nos Letramentos Críticos. Pretende-se com este estudo, fornecer informação elementar para os que desejam se engajar em pesquisas investigativas teóricas e/ou práticas acerca do tema letramentos, e considerar a possibilidade de adequar as teorias dos novos estudos de Letramentos Críticos para realizar propostas de trabalho pedagógico para o desenvolvimento dos letramentos em Língua Inglesa no contexto brasileiro.

\section{Os estudos iniciais de Letramentos - modelos autônomo e ideológico}

No final do século passado, Street (1984) investigou os trabalhos de letramento existentes à sua época, e os categorizou em dois modelos pedagógicos, atribuindo-lhes as seguintes nomenclaturas: modelo autônomo e modelo ideológico. No modelo a que chamou autônomo, o autor encontrou um trabalho cujo foco era a técnica, e cuja abordagem priorizava habilidades necessárias à codificação e decodificação dos símbolos usados para leitura e escrita, considerando o letramento uma tecnologia neutra, unidirecional em seu desenvolvimento, homogeneizadora, estável perante tempo e espaço, e independente do contexto de produção da prática social que o envolve. Street viu falhas nesse modelo, que não se preocupava com os significados do processo de socialização na construção de significados; para o autor, o letramento não pode ser desvinculado da ideologia de seu contexto imediato, como ele exemplifica a seguir:

os significados das práticas particulares e os conceitos de leitura e escrita para uma dada sociedade dependem do contexto (...) já estão intricadas numa ideologia e não podem ser 
3 "what the particular practices and concepts of reading and writing are for a given society depends upon the context (...) they are already embedded in an ideology and cannot be isolated or treated as 'neutral' or merely 'technical'". isoladas ou tratadas como 'neutras' ou meramente 'técnicas' (STREET, 1984, p. 1, tradução nossa). ${ }^{3}$

O autor vê com clareza como a troca de conteúdo significativo por meio da leitura e da escrita nas sociedades letradas não é nem pode ser considerada uma prática neutralizada. Pelo contrário, o autor parece preferir uma perspectiva dialógica, em que todos os textos podem ser considerados como "local de interação" (KOCH, 2006, p. 17), onde estão representados os discursos que interpelam os sujeitos dessa interação, fazendo de todo ato de leitura, potencialmente, um ato de confronto identitário - entre o leitor e o escritor - e de todo ato de escritura, um ato de exposição identitária. Assim, ao se desenvolver letramento em sala de aula, suponho que não se deva ignorar essas nuances dos textos que permeiam as interações sociocomunicativas para que seja possível promover a formação crítica do estudante.

Como Rajagopalan (2008) admite,

a crença na neutralidade do educador é ela mesma uma atitude política - a de não perturbar a ordem das coisas que se encontra instalada, ainda que nela possam estar abrigadas severas injustiças e arbitrariedade gritantes. (p. 111)

Compreendo que a neutralidade característica da prática de letramento autônomo pode acabar levando à manutenção dos discursos como foram estabelecidos, com suas cristalizações e posições hierárquicas representadas, omitindo o teor processual e contextual do conhecimento, que pode ser sempre passível de novas leituras, reorganizações e ressignificações variadas por parte dos alunos. O modelo de desenvolvimento de letramento autônomo apresenta a interação sociocomunicativa como pronta, estável e acabada, na qual os sujeitos já possuem seus lugares fixos, em vez de apresentá-la como 
uma prática contextual com múltiplas possibilidades de aplicação e significação. Embora reconheça o caráter comunicativo da língua e a importância do trabalho focado nas práticas comunicativas letradas, exacerbando, assim, o antigo caráter simplista da alfabetização, o desenvolvimento do letramento autônomo ainda não contempla o desenvolvimento crítico dos estudantes, pois não associa os textos e os discursos às ideologias circulantes no meio social.

Em oposição ao modelo autônomo de letramento, Street (ibidem) apresentou o que ele categorizou como modelo ideológico de letramento. Ao apresentar o modelo ideológico, o autor argumentava que o letramento deveria ser visto não como um letramento único, neutro, mas como letramentos múltiplos: atividades realizadas no cotidiano, diversificadas em seus objetivos, utilidades, propósitos e desempenhos, e cujas bases estariam na palavra escrita. Como o autor expõe, "deveríamos mais apropriadamente referir-nos a 'letramentos' em lugar de um único 'letramento'” (ibidem, p. 8, tradução nossa). ${ }^{4}$ Essa proposta vem mostrar que diferentes competências são necessárias para a interação nas práticas sociais, e que os letramentos não são práticas independentes das ideologias que permeiam o contexto, como defendem os adeptos do modelo autônomo; pelo contrário, os letramentos têm uma inter-relação de dependência e complexidade com o contexto social e com as tecnologias disponíveis para as práticas sociais. Street, nesse sentido, então, propõe que “a tecnologia, então, é uma forma cultural, um produto social cujo aspecto e influência dependem prioritariamente de fatores políticos e ideológicos" (ibidem, p. 96, tradução nossa $)^{5}$, e acrescenta que as tecnologias relacionadas às práticas de letramento são ricas e diversificadas, mas sobre o seu uso procura-se exercer controle, de maneira que indiretamente seja exercido controle também sobre as práticas socioculturais.
4 "we would probably more apropriately refer to 'literacies' than to any single 'literacy"'

5 "Technology, then, is a cultural form, a social product whose shape and influence depend upon prior political and ideological factors" 
6 "It is a social process, in which particular socially constructed technologies are used within particular institutional frameworks for specific social purposes".
Essa relação entre tecnologias e letramentos, sendo ambos controlados socialmente por instâncias políticas e ideológicas, leva o autor a estabelecer uma ideia de letramento como um processo conectado à tecnologia e, consequentemente, sempre em estado de revisão. Por esta razão, Street afirma que o letramento "é um processo social, em que tecnologias particulares socialmente construídas são usadas em estruturas institucionais particulares para propósitos sociais específicos" (ibidem, p. 97, tradução nossa). ${ }^{6}$

O autor (ibidem) apresenta, ainda, os seguintes pressupostos ao discutir o modelo ideológico de letramento: 1) o significado de letramento depende das instituições sociais que o atravessam; 2) não é possível separar letramento do significado político e ideológico que este tem em uma determinada sociedade, tratando-o como se fosse autônomo, independente das práticas sociais que implicam a ação do sujeito histórico; 3) os letramentos são pluridirecionais em seus desenvolvimentos; e 4) as práticas de leitura e escrita ensinadas em um determinado contexto dependem da estratificação social e do papel das instâncias educacionais, que permanecem ocupadas com a disseminação de conceitos que atendam aos próprios interesses.

Street ainda esclarece como o letramento foi usado para disseminar as bases elaboradas de comportamento e controle social por determinadas classes ou instituições para atender aos seus próprios interesses, como nas campanhas britânicas de letramento em séculos anteriores com vistas à dominação dos territórios conquistados, e nas campanhas protestantes para usar a promoção do letramento com propósitos religiosos, ou, ainda, no desenvolvimento do letramento no Canadá, no século XIX, quando este era usado para controle social e, assim sendo, eram cuidadosamente excluídas quaisquer menções a elementos críticos (ibidem). 
O conceito de letramento ideológico representou um avanço no entendimento da língua e da linguagem em suas relações sociais, culturais e ideológicas, e em sua relação com as perspectivas dos sujeitos. Bakhtin/ Voloshinov (1929/2006, p. 98,99) pontua que "não são palavras o que pronunciamos ou escutamos, mas verdades ou mentiras, coisas boas ou más, importantes ou triviais, agradáveis ou desagradáveis". Por esse motivo, vejo como adequado conceber o desenvolvimento dos letramentos em sala de aula de modo a contemplar as questões ideológicas que atravessam os textos circulantes na sociedade.

\section{Novos Estudos-Os Letramentos Críticos}

De acordo com estudos que vêm sendo realizados desde o final do século passado, o contexto histórico atual não suporta mais uma educação sem compromisso com equidade, justiça social, e desconstruções das identidades e dos discursos cristalizados (GIROUX, 1997; TODD, 2003). Como afirma Kenski (2007),

a escola precisa assumir o papel de formar cidadãos para a complexidade do mundo e dos desafios que ele propõe. Preparar cidadãos conscientes, para analisar criticamente o excesso de informações e a mudança, a fim de lidar com as inovações e as transformações sucessivas dos conhecimentos em todas as áreas. (p.64)

É premente hoje a necessidade de a escola se preocupar com a formação e não somente com a informação dos sujeitos, já que participamos de um mundo em transformação. Faz-se relevante investir na formação do cidadão e discutir a noção de cidadania, assim como compreender os conceitos de crítica presentes nas discussões educacionais. Segundo os novos estudos dos letramentos, existe a necessidade de se 
7 "a form of

empowerment (...)

acquiring the skills that enable one to critically examine history (...) expand the possibilities for both self-knowledge and critical and social agency”. atualizar o conceito de cidadania abandonando a antiga proposta de produzir cidadãos - proposta que investe na "uniformização de práticas, valores, conhecimentos e disposições" (KRESS, 2008, p. 120). Como sugere Giroux (2006), o desenvolvimento da cidadania inclui "uma forma de tomada de poder (...) aquisição de habilidades que possibilitem examinar criticamente a história (...) expandir as possibilidades de autoconhecimento e agência crítica e social" (p. 183, tradução nossa). ${ }^{7}$ Da mesma forma, as Orientações Curriculares para o Ensino Médio - OCEM, em sua seção Línguas Estrangeiras, afirmam que na contemporaneidade "o conceito [de cidadão] é muito amplo e heterogêneo, mas entende-se que 'ser cidadão' envolve a compreensão sobre que posição/lugar uma pessoa (o aluno/o cidadão) ocupa na sociedade" (BRASIL, 2006, p. 91). Nesse sentido, esse desenvolvimento de cidadania também envolve possibilitar ao indivíduo ser capaz de se recriar sempre, de transformar informação em conhecimentos (KRESS, 2008), e de não restringir seus interesses aos problemas locais, mas procurar ser um cidadão cuja identidade perpasse as bordas geoculturais de seu local de nascimento. É nesse sentido que Brydon (2013) indica o desenvolvimento de Letramentos Transnacionais, os quais define da seguinte maneira:

me refiro ao tipo de habilidade de construção de significado associada com aprender a trabalhar pelos discursos disciplinares especializados bem como por aqueles, mais convencionalmente associados a diferentes partes geopolíticas do mundo e às diferentes linguagens e visões de mundo associadas a elas (...) prática social, que variará de acordo com muitos contextos nos quais são exercidos (p. 3).

Nesse viés, os letramentos estão associados às habilidades de negociar discursos em ambientes plurivocais, plurilinguísticos e pluriculturais, em 
um movimento de direção oposta às tentativas de homogeneização, procurando assegurar equidade independentemente das posições de sujeito exercidas pelos interactantes, de seus registros linguísticos ou de suas identidades sociais compulsórias e volitivas (SILVA, 2012) construídas ao longo de sua história.

Discorrendo sobre as diferenças entre os mundos pré e pós-revolução tecnológica e globalização, Cope e Kalantzis (2006) indicam que a diversidade local e a conexão global apontam para a falência de padronizações, incluindo as padronizações linguísticas como modelos únicos. Os autores defendem a pluralidade na linguagem, na educação, na cultura e na escola. Ainda conforme esses autores, as habilidades mais importantes aos alunos da contemporaneidade são: 1) aprender a negociar diferenças dialetais, culturais, étnicas, regionais; 2) engajar-se em discursos de cruzamento cultural; 3) entender as relações entre as pessoas e as linguagens; e 4) estar prontos para as mudanças de código que possam ser necessárias em contextos diversificados. Essas habilidades são denominadas letramentos por esses autores. Assim, vê-se que múltiplos letramentos são necessários para as interações na contemporaneidade, não mais primando pelos paradigmas estabelecidos por uma minoria, mas procurando estabelecer o diálogo e a negociação das produções de sentido em atitudes de legitimação dos vários discursos e dos diferentes letramentos. Articulando essas premissas com o ensino de línguas, Rajagopalan (2008) indica que a atividade linguística e a atividade política são apenas "duas faces da mesma moeda" (p. 32). Para o autor, "ao falar uma língua, ao nos engajarmos na atividade linguística, estaríamos todos nós nos comprometendo politicamente e participando de uma atividade eminentemente política" (ibidem).

Essas novas reflexões levaram à proposta de letramentos críticos, que concebem os letramentos como 
práticas sociais contextualizadas. Como Lankshear e Knobel (2006) elucidam,

isso significa que letramento é realmente como uma família de práticas - letramentos (...) [que] variam de alguma forma entre si em termos de tecnologia usada (...) o conhecimento solicitado (...) as habilidades requeridas. (p. 66, tradução nossa). ${ }^{8}$

8 "This means that literacy is really like a family of practices literacies - [that] all vary to some extent from one another in terms of the technologies used (...) the knowledge drawn upon (...) and their skill requirements".

9 “(...) understood and acquired only within the context of the social, cultural, political, economic and historical practices to which they are integral"

Os autores concebem os letramentos como práticas, explicando que as práticas são resultantes da articulação entre tecnologia, conhecimento e habilidades. Esses três itens inter-relacionados, segundo os autores, influenciam as mudanças nas perspectivas dos sujeitos, suas representações, propósitos e necessidades históricas. Nesse sentido, entende-se que as várias práticas letradas são contextuais e culturais; não são universais nem pertencem a um grupo dominante, mas são locais e servem para atender a demandas locais, e, portanto, devem ter sua legitimação garantida. Lankshear e Knobel (2006) acentuam, porém, que muita gente ainda usa o termo letramento em relação ao mesmo trabalho que se fazia no século passado concernente à "alfabetização", ou seja, ainda trabalham como se o letramento fosse um conhecimento instrumental de codificar e decodificar, de relacionar grafemas a fonemas, como um saber que pode ser acabado e completo. Entretanto, como argumentam Cox e Assis-Peterson (2008, p. 33), "letrar-se, diferentemente de alfabetizar-se, que se restringe ao domínio da escrita como tecnologia, significa dominar, como usuário, a cultura escrita como um todo (...) envolve a habilidade de construção de sentido". Por esse motivo, Lankshear, Snyder e Green (2008), defendem que o letramento seja "entendido e adquirido somente dentro de um contexto de práticas sociais, culturais, políticas, econômicas e históricas das quais faz parte" (p. 28, tradução nossa). ${ }^{9}$ 
Portanto, defino letramentos como habilidades adquiridas contextual e socialmente para registrar, compartilhar, enviar, receber, negociar e comunicar produções de sentido, ressaltando que essas produções de sentido podem ser concretizadas em múltiplas modalidades verbal, gestual, sonora, espacial, visual ou multimodal. São essas concretizações multimodais de produção de sentidos que passo a chamar, então, de textos. Nesse âmbito, os textos deixam de ser apenas as expressões verbais (orais ou escritas) de sujeitos sociocomunicantes, mas têm sua categorização expandida, podendo ser encontrados nas diversas modalidades. Assim, é possível haver nas aulas de Língua Inglesa, para a concretização da prática pedagógica de ensino de língua, não somente textos verbais, que contêm palavras, mas também textos visuais, sonoros, gestuais, multimodais, enfim.

Por serem habilidades adquiridas socialmente dentro de um contexto, é importante dizer que, ao se falar em letramentos, não necessariamente estamos falando de letras, leitura e escrita de signos linguísticos - estamos falando, sim, independentemente de modalidade, de registro, comunicação, troca, negociação de produções de sentido, de representações de uma realidade atravessada por discursos contextuais e subjetivos. Esta noção é importante porque, ao se legitimarem os diversos letramentos, legitimam-se também os diversos discursos, as variadas culturas que convivem no mesmo espaço geofísico. Essa perspectiva de letramentos como locais, contextuais e multimodais, permite que se ouçam as vozes de sociedades ágrafas, cujas produções de sentido são registradas, negociadas e comunicadas sem o uso de signos linguísticos, e, ainda assim, sem que isso as torne sociedades menos elaboradas ou menos complexas que as grafocêntricas.

Partindo dessa visão, balizados no trabalhoiniciado por Street, e ressignificando as práticas pedagógicas 
para adequá-las ao cenário social e epistemológico atual, alguns pesquisadores propuseram um ensino de língua voltado para o letramento crítico, tomando por base essa perspectiva de que o letramento é uma habilidade, um conhecimento contextual para produzir sentidos. Segundo Takaki (2012, p. 59), “o letramento crítico assume um compromisso social: analisar como uma sociedade se transforma, os motivos pelos quais ela se transforma, visando, assim, a uma formação e participação ativa do cidadão em seu meio". Para a autora, desenvolver o letramento em sala de aula ultrapassa "a mera atribuição de sentido ao texto estudado", mas visa a "capacitar o leitor a participar ativamente no complexo social no qual ele interage” (p. 51). Assim, a aula de língua e o trabalho pedagógico com textos vão ao encontro da indicação que Libâneo (2011) faz de, na prática pedagógica escolar, abranger conteúdos que sejam relevantes para a prática social, ou seja, conhecimentos que provoquem modificação na prática desse aluno na sociedade em que se insere. $\mathrm{O}$ autor explica da seguinte forma:

Muitos professores entendem que ligar os conhecimentos com a realidade é ensinar apenas coisas práticas. Esta é uma visão muito estreita de relevância social. Muitos assuntos da matéria não têm vínculo direto, mas têm um efeito prático fundamental para desenvolver o pensamento teórico dos alunos. Os conhecimentos são relevantes para a vida concreta quando ampliam o conhecimento da realidade (...) a pensar a própria prática (p. 144).

Com essa visão, o ensino de língua com base nos princípios dos Letramentos Críticos caracterizase por expandir a prática operacional de produção de sentidos do aluno, explicitando uma atitude de educação linguística crítica, ao serem propostas atividades que fomentem a construção de sentidos, a pluralidade e a 
negociação de discursos na sala de aula, de modo que os conhecimentos produzidos sejam relevantes para a vida prática desses alunos, ampliando-lhes as atuações como sujeitos comunicativos, tornando-os participantes críticos em suas interações comunicativas. McCormick (1994) defende a necessidade de letramento crítico com a seguinte elucidação:

O Letramento Crítico não consiste somente em ser capaz de compreender os textos que são lidos ou ligá-los aos mundos particulares de uma pessoa. Mais que isso, ser um leitor letrado criticamente é ter o conhecimento e a habilidade de perceber a interconexão das condições sociais e as práticas de leitura e escrita de uma cultura, a capacidade de analisar essas condições e práticas, e de possuir a consciência política e crítica para tomar atitudes a favor ou contra. (p.49, tradução nossa) ${ }^{10}$

A autora acentua a relação entre ideologia e textos circulantes em uma sociedade, mostrando o quanto é importante desenvolver nesses sujeitos aprendizes a capacidade de entender a construção dos sentidos e a dinâmica discursiva na sociedade em que se inserem, tendo em vista que, para os Letramentos Críticos, o conhecimento é "construído socialmente e sempre ideológico, incompleto, deslizante, múltiplo e relativo (...) sempre passível de contestação e questionamento" (JORDÃO et al, 2013, p. 45). Nesse sentido, vejo válido perguntar para quê o aluno vai ler um determinado texto, e inspirada em Biesta (2011), questionar quais as oportunidades de ser e agir poderão resultar da prática de leitura que se propõe na sala de aula. Ensinar língua pelo viés dos Letramentos Críticos é ensinar o aluno a suspeitar de significados prontos, de sentidos já ditos ou fornecidos a priori; é possibilitar ao aluno "ler-se lendo" (MENEZES DE SOUZA, 2011a, p. 296), e produzir sentidos assegurando o direito à diversidade discursiva em
10 "Critical literacy consists not only of being able to comprehend the texts one reads or to link them with one's own personal worlds. Rather, to be a critically literate reader is to have the knowledge and ability to perceive the interconnectedness of social conditions and the reading and writing practices of a culture, to be able to analyse these conditions and practices, and to possess the critical and political awareness to take action within and against them." 
um exercício interpretativo de fazer uso da crítica, pondo em crise os sentidos fixos, cristalizados e legitimados como únicos verdadeiros. Vistos como contextuais e não universais, os letramentos não são entendidos como práticas exclusivas das culturas dominantes, mas passase a ter a compreensão de que os letramentos que são requeridos em algumas sociedades podem não ser em outras. Essa visão pode promover a percepção de que as culturas não podem ser estabelecidas em uma hierarquia vertical. Como admite Takaki (2012), "é sempre possível reinterpretar textos mediante a renovação de olhares” (p. 59). Isso significa que despertar novos olhares dos alunos, fazê-los descobrir os porquês de seus olhares e atentar aos olhares que entram em conflito com os seus próprios, talvez seja alternativa para o ensino que garanta a diversidade na sala de aula e que promova, entre esses alunos aprendizes da língua, a legitimação da diversidade e dos discursos diversos. Arrisco dizer que permitir/incentivar a multiplicidade de interpretações em sala de aula é uma forma de garantir a diversidade no microcosmo escolar, por não incentivar as polarizações mas questioná-las; por não buscar as verdades, mas os processos de construção das verdades; por não definir as respostas certas, mas admitir as várias possíveis respostas.

\subsection{Letramentos Multimodais - multiletramentos}

Embora à época de suas pesquisas iniciais, Street (1984) estivesse conectando letramento essencialmente às práticas escritas e aos textos verbais, o conceito por ele desenvolvido veio servir como base teórica para os novos estudos, que enxergam os letramentos como tendo extrapolado a dimensão puramente escrita, passando a ser constituídos por múltiplas práticas de produção de sentidos, marcadas pela multimodalidade e pela pluralidade semiótica (KLEIMAN, 2006). 
Diversos pesquisadores brasileiros da área das linguagens vêm constatando e investigando aspectos da pluralidade semiótica dos tempos contemporâneos (TAKAKI, 2012; ZACCHI, 2009; MONTE MÓR, 2008; entre outros). Bou Maroun (2007), por exemplo, aponta que "considerar somente a modalidade escrita como principal modo semiótico é explicar apenas parte do cenário da comunicação nos dias atuais" (p.78). Da mesma forma, Vieira (2007), indicando o quanto a necessidade de multiletramentos é presente na atualidade, argumenta que "a qualidade mais apreciada nos sujeitos deletramento é a capacidade de mover-se rapidamente entre diferentes letramentos", e acrescenta que "as práticas textuais (...) podem abrigar a fala, a escrita, a comunicação visual e sonora, além de utilizarem os recursos computacionais e tecnológicos" (p. 24). A respeito dessa perspectiva, parece haver concordância em Snyder (2002) quando a autora afirma que "em um mundo mediado eletronicamente, ser letrado tem a ver com entender como as diferentes modalidades são combinadas de formas complexas para criar significados" (p. 3, tradução nossa). ${ }^{11}$

Carmen Luke (2006), uma das pioneiras do movimento dos Multiletramentos, indica que as tecnologias de forma geral modelam as práticas sociais. Assim, no caso do mundo contemporâneo, com as novas tecnologias de informação e comunicação - TICs - as perspectivas de espaço, tempo, presença, ausência, além das noções de linguagem, textualidade, gêneros entre outras relacionadas à comunicação entre os seres humanos necessitam uma reformulação. Para essa autora,

essas mudanças e diferenças apontam para a necessidade de considerar uma definição expandida de letramento que dê conta das múltiplas formas de linguagens textual, gráfica e simbólica, assim como das comunidades virtuais culturalmente diversificadas no cenário midiático global. (LUKE, 2006, p. 77, tradução nossa) ${ }^{12}$
11 "in an electronic mediated world, being literate is to do with understanding how the different modalities are combined in complex ways to create meaning".

12 "These changes and differences point to the need to consider an expanded definition of literacy to take account of multiple forms of textual, graphic, and symbolic languages, as well as the culturally diverse virtual communities of the global mediascape". 
Além desses letramentos expandidos em consequência da também expansão do cenário midiático contemporâneo, alguns estudiosos, ainda veem a necessidade de exacerbar ainda mais os estudos de letramentos críticos atentando para a contextualidade dos letramentos. Nessa perspectiva, os letramentos adquirem novo entendimento, visto que, por intermédio da língua, o conhecimento e a apropriação de uma mídia que atenda à necessidade dos sujeitos de uma sociedade para produzirem conteúdos significativos, para fazerem circular os discursos e estabelecerem a troca e negociação desses conteúdos, podem ser considerados um letramento. Além disso, sendo o letramento uma prática social - e sabendo-se que toda prática social envolve conhecimento local das práticas - então os letramentos também são locais e envolvem cultura, poder, hierarquias e contextualização socioideológica. Por isso, Luke (2006) indica que a produção textual na contemporaneidade exige que novas habilidades devam ser desenvolvidas: as habilidades de importar, uploadar, downloadar, apagar, arrastar, copiar, recortar, colar tanto textos verbais quanto imagens, refazer, pesquisar etc. Acredito que isso seja letramento para a contemporaneidade. Além disso, a autora, assim como Kress (2007), indica uma forma completamente inovadora de se ler, em que não se lê somente horizontal e linearmente, procurando as informações da esquerda para a direita (ou vice-versa em algumas culturas) e de cima para baixo, mas a leitura pode ser feita multidirecionalmente e dependente da acuidade visual - haja vista as dimensões cada vez menores de gadgets para leitura - e do interesse desse novo leitor.

Requerem-se, portanto, novas práticas, letramentos novos e multimodais para combinar leitura horizontal com multidirecional utilizando as mais diversas mídias e tendo que desenvolver, a cada dia, novas habilidades. Nesse sentido, então, infiro que vivemos uma época de 
letramentos em rápida expansão, e a escola não pode ficar à margem desses novos letramentos.

\subsection{Letramento Tridimensional}

Colin Lankshear, Ilana Snyder e Bill Green (2000), percebendo, em seus estudos, a importância da pedagogia de letramentos para os tempos atuais, propuseram uma abordagem de ensino de língua a que denominaram Letramento Tridimensional, em que sugerem três dimensões da prática e da aprendizagem de língua, a saber: operacional, cultural e crítica. Essas três faces articuladas, segundo os autores, poderiam dar conta de linguagem, significado e contexto juntos.

Por dimensão operacional do letramento, os autores entendem o uso de ferramentas, procedimentos e técnicas do letramento. Por ferramentas, não se entende somente ferramentas das novas tecnologias, mas também do sistema da língua, tais como funcionamento do alfabeto, o lápis, a caneta, o sistema fonológico, o computador, como se usam os programas disponíveis para a interação social e a produção de sentidos, como utilizar o teclado, como se lê e como se escreve (da esquerda para a direita, de cima para baixo, no caso do inglês e do português), como se pronunciam as palavras etc. Esse conhecimento operacional é muito importante no processo de letramento porque permite entender a língua como um sistema que é, as possíveis relações sintagmáticas do sistema, as ferramentas que possibilitam as expressões etc.

Por dimensão cultural, entende-se a competência para fazer parte da prática social, pois como pontuam os autores, "letramento é mais que ser capaz de operar os sistemas da língua e da tecnologia: tais capacidades operacionais estão sempre a serviço de formas 'autênticas' de significado e prática" (ibidem, p. 31, tradução nossa). ${ }^{13}$ Sendo assim, a dimensão cultural expande a noção de
13 "literacy is always more than Just being able to operate language and technology systems: such operational capacities are always in the service of 'authentic' forms of meaning and practice" 
letramento, passando do operacional de codificar e decodificar, produzir e receber textos, usar ferramentas e entender os sistemas, para a aplicação desses elementos a práticas sociais autênticas, a situações reais de uso, que tragam consigo a carga cultural, a constituição social por meio da língua. Ademais, são focadas questões que relacionem conhecimento e cultura, e o letramento é visto, nessa dimensão, como uma prática sociocultural, podendo-se enxergar a conexão da língua com a cultura e constatar que "a comunicação é um processo cultural" (LARAIA, 2003, p. 52). Esse autor ainda destaca que

o modo de ver o mundo, as apreciações de ordem moral e valorativa, os diferentes comportamentos sociais e mesmo as posturas corporais são assim produtos de uma herança cultural, ou seja, o resultado da operação de uma determinada cultura. (LARAIA, 2003, p. 68)

Concordando com a premissa acima, os focos, na dimensão cultural do letramento tridimensional, são direcionados a questões de prática e de significados reais, conectando linguagem a comportamentos sociais e a valores, por exemplo, procurando desnudar os aspectos culturais presentes na linguagem.

Na dimensão crítica do letramento tridimensional, não somente são apresentados os aspectos culturais das práticas socioculturais ligadas à língua, mas esses aspectos, assim como os discursos que os constituem com seus valores éticos e estéticos, são questionados e postos em análise, pois que todas as práticas sociais - e se os letramentos estão sendo vistos sob perspectiva de uma prática social, também estes - incluem valores, propostas, seleções, distribuições, perspectivas e regras, escolhidas, mesmo que compulsoriamente, pelos participantes da interação social, em uma escala de importância que obedece a hegemonias estabelecidas e legitimadas, de acordo com as 
relações de poder vigentes. Nessa dimensão, a promoção do letramento leva em conta que as práticas discursivas podem ser construídas, desconstruídas, alteradas e transformadas pelos atores sociais, e que as hierarquias são passíveis de serem redesenhadas nas sociedades a partir da transformação e redimensionamento dos papéis desses atores, conforme seu próprio julgamento, e não somente conforme julgamentos já prontos, estabelecidos e ratificados pela coletividade; colocam-se em risco os discursos cristalizados, legitimados e historicamente construídos, procurando permitir que os alunos descubram que "as diferentes culturas e subculturas moldam quem, o quê, e quando as pessoas leem por propósitos sociais particulares" (LUKE E FREEBODY, 1999, p. 195, tradução nossa). ${ }^{14}$ Nesse sentido, a percepção crítica e/ ou a conscientização dessas construções e reconstruções torna-se relevante.

É importante ressaltar que os autores não estabelecem um princípio de linearidade, hierarquia nem gradação para o trabalho com o Letramento Tridimensional, assim como não estabelecem qualquer prioridade de uma dimensão sobre a outra (LANKSHEAR, SNYDER e GREEN, 2000), mas sustentam que as dimensões podem e devem ser trabalhadas conjuntamente, sem pré-requisito para se trabalhar a dimensão crítica e sem aferir-lhe a condição de última etapa em um processo educativo. O que se compreende é que não se espera que sejam trabalhadas as três dimensões como se fossem estágios diferentes e independentes no trabalho pedagógico, mas considerando-as três aspectos de um único trabalho pedagógico.

O trabalho com o Letramento Tridimensional, abarcando as dimensões operacional, cultural e crítica dos letramentos, vem a ser um modelo holístico que tenta trazer uma visão abrangente dos letramentos e sua função na sociedade contemporânea, que é caracterizada por
14 "Different cultures and subcultures frame up who, what, and when people read for particular social purposes" 
instabilidades em uma ordem semiótica com configurações diferentes das do século passado. A noção de letramento tridimensional vem, sob minha perspectiva, alcançar um passo além das práticas de letramento tradicionais, por focar no saber aplicado à prática social, e à competência e agência para uso amplo. O Letramento Tridimensional engloba competência técnica de saber onde, quando e como usar a linguagem, entender a adequação de práticas sociais, e, compreender as relações de poder existentes nos diversos textos circulantes nas práticas sociocomunicativas entre os sujeitos.

\section{Considerações Finais}

Como já mencionado, a contemporaneidade demanda uma escola engajada em assegurar a diversidade, em discutir a cidadania, em produzir sentidos nas mais diversas modalidades e em entender e problematizar as formações discursivas da sociedade. Não se pode mais aceitar uma escola que se suponha neutra em sua prática pedagógica. Inclusive porque supor-se neutra já é, por si só, assumir o posicionamento da isenção. A conexão global de sujeitos sociais com os mais variados valores e perspectivas éticas e estéticas produz a real necessidade de legitimação dos diversos discursos, de negociação das produções de sentido e de relativização e problematização das cristalizações discursivas. Esses novos estudos de letramentos podem dar suporte às práticas pedagógicas interessadas na transformação dos sujeitos e na ampliação de sua atuação crítica nas sociedades porque procuram desmistificar ou desvelar as hierarquias estabelecidas, mostrando as possibilidades de construção, reconstrução, desconstrução e reorganização das relações de poder implícitas nos atos comunicativos, nas práticas sociais que, na contemporaneidade, são mediadas também pelas novas tecnologias de informação e comunicação. Reconhecemos que esses estudos de letramentos estão em 
plena expansão e longe de serem esgotados; por isso, o objetivo deste trabalho foi oferecer uma análise teórica preliminar das tendências pedagógicas contemporâneas para o desenvolvimento dos letramentos para a sala de aula de Língua inglesa em contexto nacional brasileiro, e incentivar o leitor às suas próprias investigações bibliográficas e aplicações práticas para procedimentos pedagógicos em sala de aula de língua inglesa, com vistas a promover a educação formal crítica e de boa qualidade para formar cidadãos éticos, sujeitos sociais coenunciadores críticos, conectados globalmente e agentes locais. 


\section{Referências:}

BAKHTIN, Mikhail (VOLOSHINOV). Marxismo e Filosofia da Linguagem. 12 ed. São Paulo: Hucitec, 1929/2006.

BIESTA, Gert. Good education in na age of measurementethics, politics, democracy. Colorado: Paradigm Publishers, 2010.

BOU MAROUN, Cristiane R.G. O texto multimodal no livro didático de Português. In: VIEIRA, J. A. et al. Reflexões sobre a Língua Portuguesa - uma abordagem multimodal. Petrópolis, RJ: Vozes, 2007.

BRASIL. Secretaria de Educação Básica. Orientações curriculares para o ensino médio - OCEM: linguagens, códigos e suas tecnologias. Brasília, DF: Ministério da Educação, Secretaria de Educação Básica, 2006.

BRYDON, Diana. Desenvolvendo letramento transnacional por meio do ensino do Inglês. Trad.: Ruberval Maciel. In: TAVARES, R. R.; BRYDON, D. Letramentos Transnacionais: mobilizando conhecimento entre Brasil/Canadá. Maceió: Edufal, 2013.

COPE, Bill \& KALANTZIS, Mary (orgs.). Multiliteracies: literacy learning and the design of social futures. New York: Routledge, 2006.

COX, Maria Inês Pagliarini e ASSIS-PETERSON, Ana Antonia. O drama do ensino de inglês na escola pública brasileira. In: ASSIS-PETERSON, Ana Antonia. Línguas Estrangeiras: para além do método. São Carlos, SP: Pedro e João Editores / Cuiabá, EdUFMT, 2008.

GIROUX, Henry. Os professores como intelectuais: rumo a uma pedagogia crítica da aprendizagem. Porto Alegre: Artes Médicas, 1997.

2006. . The Giroux Reader. Colorado: Paradigm Publishers, 
JORDÃO, Clarissa Menezes; MARTINEZ, Juliana Zeggio; HALU, Regina Celia. Formação “desformatada” - práticas com professores de língua inglesa. Campinas, SP: Pontes, 2011.

JORDÃO, Clarissa Menezes et al. O PIBID nas aulas de inglês: divisor de águas e formador de marés. Campinas, SP: Pontes, 2013.

KATO, Mary. No mundo da escrita: uma perspectiva psicolinguística. 2 ed. São Paulo, Ática, 1986.

KENSKI, Vani Moreira. Educação e Tecnologias: o novo ritmo da informação. 2 ed. Campinas, SP: Papirus, 2007.

KLEIMAN, Ângela (org). Os significados do letramento. Campinas, SP: Mercado das Letras, 2006.

KOCH, Ingedore. Desvendando os segredos do texto. 5 ed. São Paulo: Cortez, 2006.

KRESS, Gunther, VAN LEEUWEN, Theo. Reading images: the grammar of visual design. London \& New York: Routledge, 2007.

LANKSHEAR, Colin \& KNOBEL, Michelle. New Literacies: everyday practices \& classroom learning. 2 ed. McGraw Hill, 2006.

LANKSHEAR, Colin, SNYDER, Ilana \& GREEN, Bill. Teachers and Technoliteracy - managing literacy, technology and learning in schools. Sydney: Allen \& Unwin: 2000.

LARAIA, Roque de Barros. Cultura - um conceito antropológico. 16 ed. Rio de Janeiro: Jorge Zahar, 2003.

LIBANEO, José Carlos. Didática. 33 reimpressão. São Paulo: Cortez, 2011.

LUKE, Allan \& FREEBODY, Peter. Shaping the social practices of reading. In: MUSPRATT, Sandy, LUKE, Allan \& FREEBODY, Peter (eds). Constructing critical literacies: 
teaching and learning textual practice. New Jersey: Hapton Press, 1999.

LUKE, Carmen. Cyber-schooling and technological change. In: COPE, Bill and KALANTZIS, Mary. Multiliteracies. London \& New York: Routledge, 2006. pp. 69-91.

McCORMICK, Kathleen. The culture of reading and the teaching of English. Manchester: Manchester University Press, 1994.

MENEZES DE SOUZA, Lynn Mario Trindade. O professor de inglês e os letramentos no século XXI: métodos ou ética? In: JORDÃO, Clarissa Menezes; MARTINEZ, Juliana Zeggio; HALU, Regina Celia. Formação "desformatada" - práticas com professores de língua inglesa. Campinas, SP: Pontes, 2011a.

. Para uma redefinição de Letramento Crítico: conflito e produção de significação. In: MACIEL, Ruberval Franco; ARAUJO, Vanessa de Assis. Formação de professores de línguas: ampliando perspectivas. Jundiaí, SP: Paco, $2011 \mathrm{~b}$.

MONTE MÓR, Walkyria. Critical Literacies, Meaning Making and New Epistemological Perspectives. In: Revista Electrónica Matices en Lenguas Extranjeras. no 2, Dezembro, 2008.

. Critical literacies in the Brazilian university and in the elementary/secondary schools: the dialectics between the global and the local. In: MACIEL, Ruberval Franco; ARAUJO, Vanessa de Assis (Eds.). Formação de professores de línguas: expandindo perspectivas. Jundiaí, SP: Paco Editorial, 2011.

NEW LONDON GROUP. A pedagogy of multiliteracies:designing social futures. In: COPE, Bill \& KALANTZIS, Mary (orgs.). Multiliteracies: literacy learning and the design of social futures. New York: Routledge, 2006.

RAJAGOPALAN, Kanavilil. Por uma linguística crítica: linguagem, identidade e a questão ética. São Paulo: Parábola, 2008. 
SILVA, Simone Batista. Da técnica à crítica: os Letramentos Críticos na formação de professores de inglês. Porto Alegre: Editora da Oficina, 2012.

SNYDER, Ilana. Silicon Literacies - communication, innovation and education in the electronic age. London and New York: Routledge, 2002.

SOARES, Magda. Linguagem e escola - uma perspectiva social. 7 ed. São Paulo: Ática, 1989.

STREET, Brian. Literacy in theory and practice. Cambridge: CUP, 1984.

TAKAKI, Nara. Letramentos na sociedade digital: navegar é e não é preciso. Jundiaí, SP: Paco, 2012.

TODD, Sharon. Learning from the other: Levinas, psychoanalysis, and ethical possibilities in Education. Albany, NY: State University of New York Press, 2003.

VIEIRA, Josenia Antunes et al. Reflexões sobre a Língua Portuguesa - uma abordagem multimodal. Petrópolis, RJ: Vozes, 2007.

ZACCHI, Vanderlei. Imagem e movimento: o modo visual na construção da identidade do sem-terra. In: Revista Brasileira de Linguística Aplicada, Belo Horizonte, v. 9, n. 2, p. 415-439, 2009.

Recebido em 27/02/2014

Aceito para publicação em 28/07/2014 